\title{
Budget Impact of Intravenous Iron Therapy with Ferric Carboxymaltose in Patients with Chronic Heart Failure and Iron Deficiency in Romania
}

\author{
László Lorenzovici ${ }^{1,2}$, Andrea Székely ${ }^{2}$, Szabolcs Farkas-Ráduly², Ciprian Jitaru ${ }^{3}$, \\ Marcell Csanádi ${ }^{4}$ \\ ${ }^{1}$ Faculty of Technical and Human Sciences, Sapientia University, Târgu Mureș, Romania \\ ${ }^{2}$ Syreon Research Romania, Târgu Mureș, Romania \\ 3 Vifor Pharma Romania, Cluj-Napoca, Romania \\ ${ }^{4}$ Syreon Research Institute, Budapest, Hungary
}

\section{ABSTRACT}

Background: Ferric carboxymaltose (FCM) treatment in case of iron deficient (ID) patients with chronic heart failure (CHF) has shown great promise according to the findings of recent studies in improvement of symptoms and quality of life, New York Heart Association (NYHA) classification, and exercise capacity. Aim of the study: The purpose of the current study is to assess the budget impact of treating CHF patients with FCM in a sample of Romanian hospitals. Material and methods: Calculations have been based on the budget impact model developed by Theidel et al. The assumptions and clinical outcomes of the current study were based on a multivariate statistical approach used in the same German study. The predicted outcomes were based on data pooled from four double-blind randomized controlled trials. The time horizon of the model was 1 year. Budget impact calculations were performed from the public payer perspective. Two scenarios have been handled: one without applying the Clawback tax and one with applying the tax to the cost of medication. Results: The yearly budget impact of FCM vs. no iron-replacement treatment without applying the tax ranged between $€ 678,383$ and $€ 641,588$ for 1,000 patients, resulting in $€ 37$ of additional costs per patient per year. The yearly budget impact of FCM vs. no iron-replacement treatment with applying the tax ranged between $€ 616,934$ and $€ 641,588$ for 1,000 patients, resulting in $€ 9$ of cost reduction per patient per year. Key cost drivers included the cost of outpatient visits and the cost of hospitalization due to HF worsening. Sensitivity analysis for both scenarios proved the robustness of the results. Conclusions: The FCM treatment of CHF patients has a moderate budget impact. Moreover, this budget impact/saving translates into a reduction of the rate and length of hospitalization stay and a better symptomatic profile of the patients.

Keywords: heart failure, iron deficiency, treatment cost, budget impact, ferric carboxymaltose, Romania

\section{ARTICLE HISTORY}

Received: September 17, 2019

Accepted: December 13, 2019

\section{CORRESPONDENCE}

László Lorenzovici

Str. Vulcan nr. 20

540074 Târgu Mureș, Romania

Tel: +40784208810

E-mail: laszlolorenzovici@gmail.com 


\section{INTRODUCTION}

Chronic heart failure (CHF) is a complex, malignant clinical syndrome, resulting in the heart's inability to provide proper output. In spite of the continuous development of new therapies addressed to CHF, the mortality of this disease remains very high, and the episodes of acute decompensation leading to acute pulmonary edema are quite frequent. As a result, the number of hospital readmissions in emergency conditions is increasing, which directly impacts the cost of healthcare in this patient population. The symptoms vary depending on which ventricle is affected. Common signs and symptoms include dyspnea, coughing, wheezing, lower extremity edema, fatigue, nausea, and palpitation. ${ }^{1}$ In developed countries, the lifetime risk of chronic heart failure for men and women is 1 in 5, the risks being as high for women as for men. ${ }^{2}$ In order to assess the severity of CHF, it is recommended to use the New York Heart Association (NYHA) functional classification, which is important for the diagnosis and management of the disease, as well as setting a prognosis. ${ }^{3}$

In Romania, heart failure (HF) can be considered a severe condition, resulting in high mortality and readmission rates. According to the published literature regarding the epidemiological data on CHF in Romania, $4.7 \%$ of the population over the age of 35 is diagnosed with the disease. The 1-year mortality for hospitalized CHF patients has been estimated to $6 \%$, and $8.9 \%$ of the patients are readmitted. 4 There is no HF registry in Romania, as there is in other countries; however, there have been several studies assessing the local situation. Recent estimates show an incidence of $0.146 \%$ and a prevalence of $1.76 \%$ for CHF, with an approximate number of 800,000-900,000 patients. ${ }^{5}$ The incidence of $\mathrm{CHF}$ is continually increasing, which may be the result of the aging of the population and the increase of the survival of myocardial infarction patients. ${ }^{6}$

Iron deficiency (ID) is an important comorbidity of CHF. A pooled analysis of 1,506 patients has found that about $50 \%$ of CHF patients are iron-deficient, and ID has been found to be connected to the severity of CHF (expressed in NYHA classification). ${ }^{7}$ Similar results were obtained by another study, conducted in the United Kingdom by Cleland et al. on 4,456 patients, where $43.2-68.0 \%$ of the anemic CHF patients had ID. ${ }^{8}$ Further studies have found that iron homeostasis disorders are correlated with NYHA class, an increased risk of anemia, and the progression of CHF. ${ }^{9}$ Another study of 546 patients has concluded that in case of systolic CHF, ID is quite common, and it represents a predictor for a negative outcome. ${ }^{10}$ The health-related quality of life (HRQOL) of CHF patients is also affected by ID. A study of 552 patients has found that the HRQoL of ID patients is significantly worse compared to non-ID CHF patients, especially because of the negative impact on the physical dimensions of health. ${ }^{11}$

Various treatment options are accepted in case of ID patients; however, intravenous iron is usually preferred. A meta-analysis of two studies has shown that, when compared to placebo, the intravenous ferric carboxymaltose (FCM) treatment of CHF patients with ID results in the reduction of hospitalizations due to worsening CHF. ${ }^{12}$ A study of 459 patients has shown that $50 \%$ of the patients treated with FCM reported highly or moderately improved health state per the Patient Global Assessment compared to $28 \%$ of the placebo group. ${ }^{13}$ Another randomized clinical trial, with 304 patients, has proven that the FCM treatment of iron-deficient CHF patients results in the improvement of functional capacity, quality of life, and symptoms, and the treatment may also reduce the rate of hospitalizations resulting from the worsening of CHF. ${ }^{14}$

At this stage, there is minimal to no information available regarding the budget impact of FCM treatment in Romania. Hence, the main objective of the study is to assess the costs of treating CHF patients with FCM through a budget impact model (BIM).

\section{METHODS}

We performed cost measurement analysis in 8 Romanian hospitals, of different size/category and of various geographical locations. Of these 8 public hospitals 3 are town/ city hospitals, 3 county/municipal hospitals, and 2 clinical hospitals.

In Romania, the financing of hospitalized patients is covered from various public sources, including the $\mathrm{Na}-$ tional Health Insurance House (NHIH, DRG and wage subvention), Ministry of Health (through national health programs and the financing of emergency care units), and local authorities (through arrears covering operating expenses), thus a complex public payer stakeholder milieu. The financing rules ${ }^{15,16}$ set forward by the NHIH are not recommended to be used as a basis for any economic evaluation/cost analysis from the public payer perspective, as the inpatient care has other revenue sources as well, such as subsidies covering the increase of salaries and national health programs financing the treatment of specific ailments. All in all, the total sum of financing is covered by the government, so the direct cost measure- 
ment is in fact used to closely approximate the public payer perspective.

Patient selection from these hospitals has been based on the ICD-10 diagnosis codes for heart failure, regardless whether the diagnosis of chronic heart failure was primary or secondary. At this stage we did not separate the patients who received FCM during their hospitalization from those who did not, as the volume of drugs administered in the selected hospitals was negligible.

The calculations are based on the actual dosage used in the Romanian medical setting. However, additional calculations were performed to include the study dosage of 1,679 mg FCM.

\section{HOSPITALIZED PATIENT POPULATION}

The main scope of the analysis is to assess the total cost of the treatment of CHF patients according to NYHA class. Based on the patient selection criteria, a total number of 8,494 patients have been included in the study. Table 1 represents their distribution according to the treating institution and NYHA class. This patient population was used only for the direct cost measurement in order to adapt the German study to the costs specific to the Romanian healthcare system.

\section{MODEL INPUTS}

\section{CLINICAL OUTPUT PARAMETERS}

The key clinical parameters were based on the data used by the budget impact model of Theidel et al. ${ }^{17}$ The key clinical outcomes to feed the BIM are the probabilities for the patients to be in a specific NYHA class (derived from the multivariate statistical analysis), death over time, rate of hospitalization due to the worsening $\mathrm{CHF}$, and average length of stay (ALOS). All these data have been taken from the BIM model of Theidel et al.

\section{ECONOMIC PARAMETERS}

\section{Cost of FCM treatment and the impact of Clawback}

For the budget impact calculations, the wholesaler price of FCM has been used as an input of the model.

As a special situation in case of the financing of the Romanian healthcare system, when it comes to the costs of drugs and medication, there is a special tax that needs to be taken into calculation: the Clawback tax, applied to all drugs and medication. The objective of this tax is to maintain the drugs and medication expenditure of the NHIH at a sustainable level. The expenditure above a specific threshold needs to be paid back by the pharmaceutical companies to the NHIH in the form of this tax. Since this is a more specific case, the budget impact calculations have been performed in two scenarios: both with and without this tax.

In order to calculate the exact cost for the public payer, the price of the medication needs to be reduced by the rate of the Clawback tax of $24.13 \%$ for Q1 of 2018 , as this is paid back to the public payer by the manufacturer. The mean cumulative dose of FCM measured in Romania has been of $958 \mathrm{mg}$, which is multiplied by the mean cost per $\mathrm{mg}$ (€0.077). On the other hand, if the calculations are performed without considering the Clawback, the mean cost per mg of FCM becomes €0.102.

The dosage of FCM was subject to study, and the exact dose prescribed to Romanian patients has been analyzed based on the official hospital drug consumption reports (reported to the NHIH) of 8 hospitals. According to the conclusions of this study, the average dosage the patients are prescribed is of $958 \mathrm{mg}$.

\section{Cost of outpatient visit}

In order to determine the cost of an outpatient visit, a panel of experts has been interviewed, resulting in a list of services provided per each NYHA class. The following cost elements have been taken into account for the cost

TABLE 1. Patient distribution according to the treating hospital and NYHA class

\begin{tabular}{lcccccc}
\hline Hospital type & \multicolumn{4}{c}{ NYHA class } & \multirow{2}{*}{$\begin{array}{c}\text { Number of } \\
\text { cases }\end{array}$} \\
\cline { 2 - 5 } & I & II & III & IV & \\
\hline City/town hospital & 125 & 697 & 485 & 181 & 1,488 \\
County/municipal hospital & 466 & 2,784 & 2,150 & 507 & 5,907 \\
Clinical hospital & 148 & 612 & 289 & 50 & 1,099 \\
Total & $\mathbf{7 3 9}$ & $\mathbf{4 , 0 9 3}$ & $\mathbf{2 , 9 2 4}$ & $\mathbf{7 3 8}$ & $\mathbf{8 , 4 9 4}$ \\
\hline
\end{tabular}


calculation: outpatient consultation, electrocardiogram, cardiac echography, laboratory analysis (complete blood count, urea/BUN, serum creatinine, sodium, potassium, aspartate aminotransferase, alanine aminotransferase, NT-pro-BNP, INR, Holter monitoring, cardiac CT scan). The cost of the outpatient visit has been calculated based on actual cost data instead of the reimbursement fee paid by the NHIH, for each cost element.

\section{Cost of home visits}

The cost of a home visit has been determined at a value of $€ 7.16$, the reimbursement fee of the NHIH for healthcare services of this kind, as no direct cost data was available.

\section{Cost of hospitalization due to CHF worsening}

The cost of hospitalization has been calculated based on actual cost data from 8 hospitals ( 2 clinical level hospitals, 3 county level hospitals, 3 small municipal hospitals). The total hospitalization cost is made up of the following cost components: cost of the hospital stay, cost of ICU stay, cost of diagnostics, and overhead costs. In case of inpatient care, the cost of medication is covered by one of the financing mechanisms (DRG, chronic financing, or national health program). The wages and salaries of the employees in public healthcare units have been measured for the period of the analysis.

Each case of CHF has been identified in these 8 hospitals for the period analyzed, resource use was attributed to these cases, and unit costs were attributed according to the resource use. The NYHA class was known for each case, thus costs could be calculated according to the NYHA class.

The cost of hospitalization also included the cost of one-day hospitalization, which was calculated based on actual hospital costs.

\section{Cost of medication per year}

The yearly medication cost of CHF patients has been calculated based on the actual prescriptions for patients, only considering the medication prescribed for the treatment/management of CHF, according to the NYHA class. These costs only include the reimbursement offered by the $\mathrm{NHIH}$, not considering the co-payment paid by the patients. Calculations have been performed in two distinct scenarios: one without considering the Clawback and another, in which the cost of the medication is diminished by the Clawback tax rate for Q1, 2018.

\section{RESULTS}

\section{RESULTS OF THE BUDGET IMPACT MODEL USING REAL WORLD DOSAGE DATA}

The total cost of the treatment of 1,000 CHF patients without FCM has been $€ 641,588$ without the Clawback tax (Table 2) and €625,748 with the Clawback (Table 3).

Due to the improved disease state and lower rate of hospitalization, the introduction of FCM treatment resulted in a net healthcare cost reduction to the value of $€ 484,278$, resulting in a total healthcare cost reduction of $€ 157,309.79$ when not applying the Clawback, and $€ 156,081.67$ after applying the Clawback. This cost reduction was driven by reductions in outpatient visit costs (€91,749.90), hospitalization costs due to CHF worsening (€59,368,76), home visit costs $(€ 1,101.53)$, and cost of CHF-related medication ( $€ 5,089.61$ when not applying the Clawback and €3,861.49 after applying the Clawback tax). All these cost savings are reduced by the cost of the FCM treatment, of a grand total of $€ 194,104.54$ when calculating with the full price, and $€ 147,267.12$ after decreasing the price with the Clawback tax.

When treating 1,000 patients with FCM for a year, without considering the Clawback, the net cost is $€ 36,794.75$, compared to no iron treatment, meaning that administering FCM for a year to a patient has an additional cost of $€ 37$. If the percentage for the Clawback is also considered, the calculations actually show a net saving of $€ 8,814.55$, which translates into approximately $€ 9$ of cost saving per each FCM-treated CHF patient.

\section{RESULTS OF THE BUDGET IMPACT MODEL USING STUDY DOSAGE}

A scenario analysis has been performed regarding the dosage of FCM. When the study dosage of $1,679 \mathrm{mg}$ is added as an input data to the model, if 1,000 patients are treated with FCM for a year, without considering the Clawback tax, the net cost for FCM patients is $€ 182,879$, meaning that administering FCM for a year to a patient has an additional cost of $€ 183$. If the percentage for the Clawback is also considered, the calculations show a lower additional cost of $€ 102,020$, which translates into approximately $€ 102$ of extra cost per each FCM-treated CHF patient.

\section{SENSITIVITY ANALYSIS}

Deterministic sensitivity analysis (DSA) has been performed regarding the parameters that have the greatest 

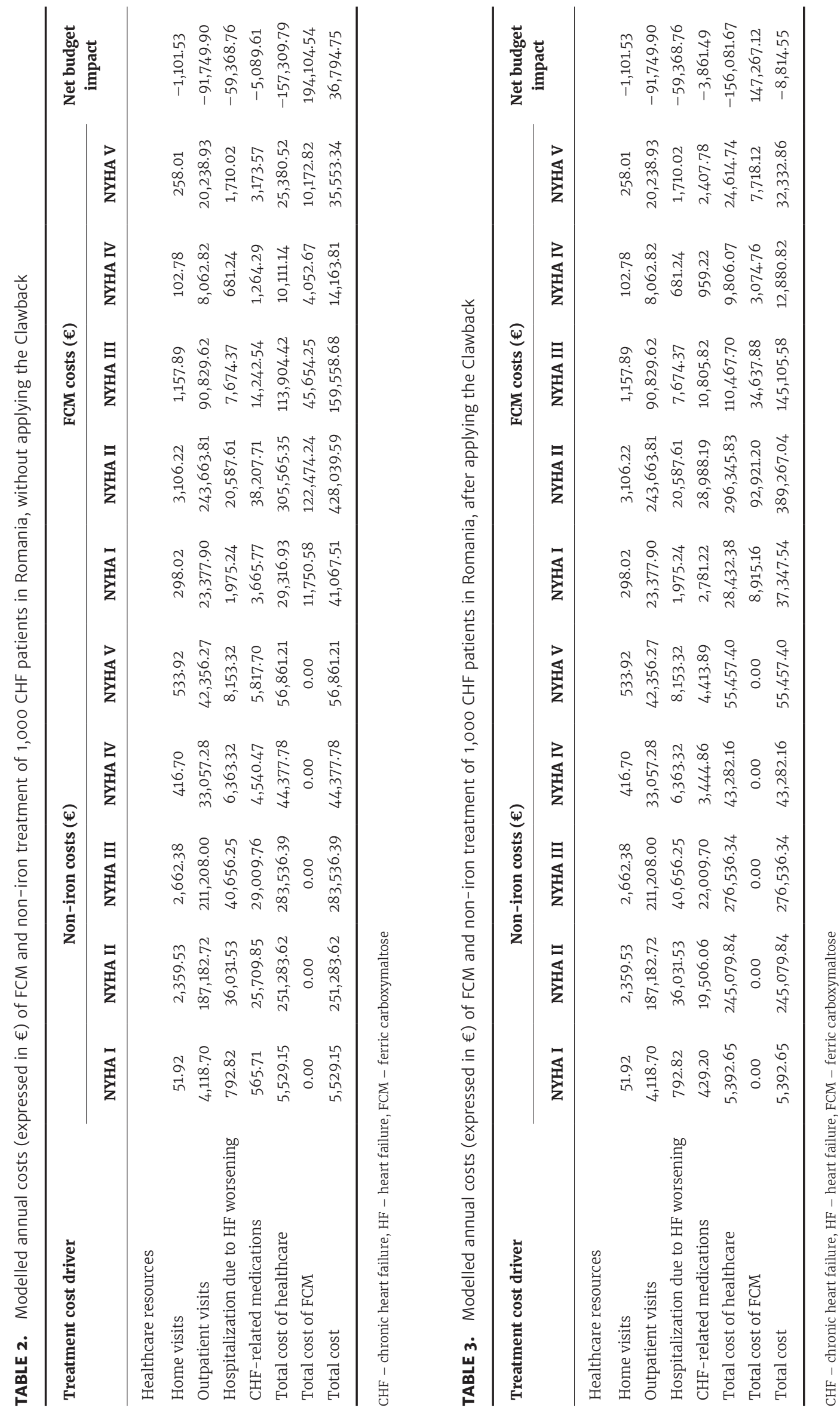


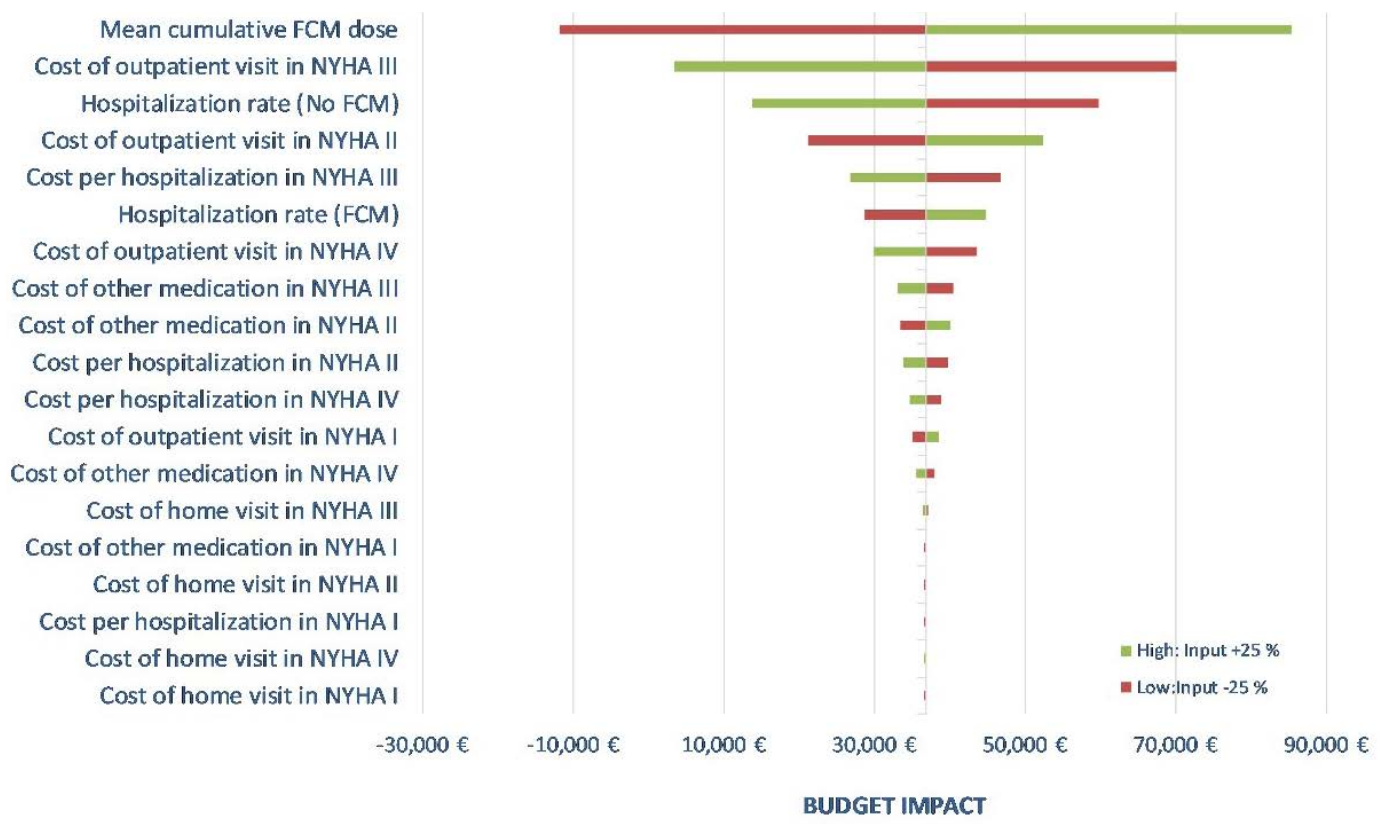

FIGURE 1. Results of the deterministic sensitivity analysis on the influential parameters regarding the budget impact of FCM use in Romania (without applying the Clawback tax)

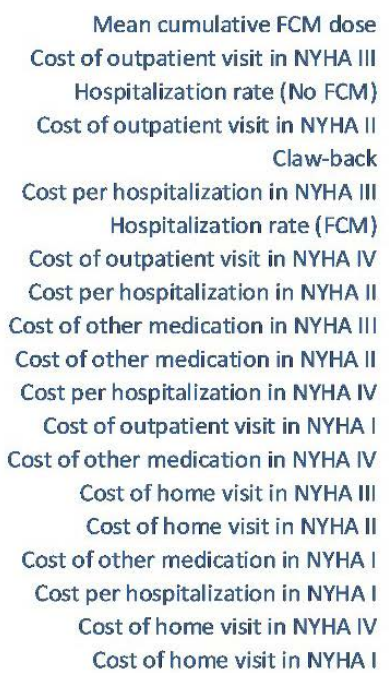

Mean cumulative FCM dose Cost of outpatient visit in NYHA III Hospitalization rate (No FCM) Cost of outpatient visit in NYHA II Claw-back Cost per hospitalization in NYHA III Hospitalization rate ( $F C M$ ) Cost of outpatient visit in NYHA IV Cost per hospitalization in NYHA II Cost of other medication in NYHA III Cost of other medication in NYHA II Cost per hospitalization in NYHA IV Cost of outpatient visit in NYHA I Cost of other medication in NYHA IV cost of home visit in NYHA III Cost of home visit in NYHA II Cost of other medication in NYHA I Cost per hospitalization in NYHA I Cost of home visit in NYHA IV cost of home visit in NYHAI

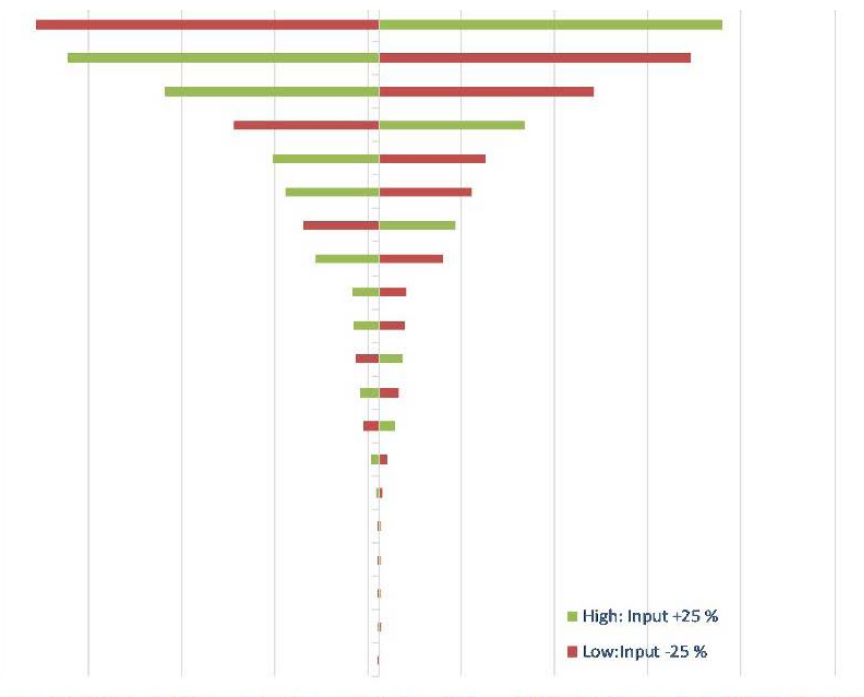

BUDGET IMPACT

FIGURE 2. Results of the deterministic sensitivity analysis on the influential parameters regarding the budget impact of FCM use in Romania (after applying the Clawback tax)

influence on the financial outcome of the budget impact calculations. This was run for both scenarios, with and without applying the Clawback tax (Figure 1 and Figure 2).

Figure 1: Results of the deterministic sensitivity analysis on the influential parameters regarding the budget impact of FCM use in Romania (without applying the Clawback tax)
According to the results of the DSA for the scenario without the Clawback tax, the mean cumulative dose of FCM administered to the patients has the highest impact on the healthcare budget of the NHIH. Assuming a decrease of the dose by $25 \%$, the budget impact would be reduced by $€ 11,731$, while an increase of this parameter by $25 \%$ would result in an increase of the budget impact 
by €85,321. Other important parameters, but with slightly lower impact are the cost of outpatient visit in NYHA III $(+25 \% € 3,386 ;-25 \% € 70,203)$ and the hospitalization rate (no FCM) (+25\% €13,795; -25\% €59,794).

According to the results of the DSA for the scenario with applying the Clawback tax, the mean cumulative dose of FCM administered to the patients has the highest impact on the healthcare budget of the NHIH (just as in case of the scenario without applying the Clawback tax). Assuming a decrease of the dose by $25 \%$, the budget impact would be reduced by $€ 45,631$, while an increase of this parameter by $25 \%$ would result in an increase of the budget impact by $€ 28,002$. Other important parameters, but with slightly lower impact are the cost of outpatient visit in NYHA III $(+25 \% €-42,223 ;-25 \% € 24,594)$ and the hospitalization rate (no FCM) $(+25 \% € 14,185 ;-25 \%$ $€-31,814)$. The Clawback tax also has great impact on the outcome of the calculations; a $25 \%$ increase results in a reduction of the budget impact of $€ 20,217$, while a reduction of $25 \%$ results in an increase of the budget impact of $€ 2,588$.

\section{DISCUSSION}

This is the first study to assess the budget impact of the use of FCM on CHF patients in Romania from a public payer perspective and using actual, direct cost measurement data. According to the results of this study, the extra costs associated with prescribing FCM to CHF patients during the first year of treatment are minimal. The findings of this study are consistent with the conclusions of Theidel et $a .^{17}$ in terms of the total net cost, in case of which the yearly budget impact has been of €40,031 (compared to the Romanian results of $€ 36,795$ when not considering the Clawback tax and $€ 8,815$ when considering the Clawback tax). Another adaptation of the BIM model has been performed for France as well, ${ }^{18}$ which has shown a cost reduction for FCM patients of $€ 5$ per patient, using the real-world dose of $925 \mathrm{mg}$ (compared to the Romanian results of $€ 37$ when not considering the Clawback tax and $€ 9$ when considering the Clawback tax). A similar BIM model has been applied in Austria as well, in case of which there was an overall saving effect of $€ 225,115$ in the first year (calculated for 2014). ${ }^{19}$

The cost element with the highest contribution to the estimated total costs has been outpatient visits for both the Clawback and no-Clawback scenarios (with a total cost of $€ 477,923$ for the no-FCM group and $€ 386,173$ for the FCM group) (Table 3). On the other hand, there is also great potential for cost saving for this parameter as well, of $€ 91,750$. Compared to the patients who did not receive FCM treatment, there is an additional cost element of $€ 194,105$ of the cost of the medication itself for the noClawback scenario and $€ 147,267.12$ for the Clawback scenario. Summing up all costs and comparing the costs of the no-FCM arm and the FCM, it results a net cost of $€ 37$ for the no-Clawback scenario, and a cost reduction of $€ 9$ for the Clawback scenario, per patient during the first year of treatment.

Several cost-effectiveness studies have been performed for FCM as well. According to the one performed for Austria, ${ }^{19,20}$ for a 4-year time horizon, based on the data of the FAIR-HF and CONFIRM-HF pivotal studies, the incremental cost-effectiveness ratio (ICER) of the FCM treatment compared to no treatment has been of $€ 16,921.62$, which is below the cost-effectiveness threshold set up by the National Institute for Health and Clinical Excellence (NICE) of $€ 22,200-€ 33,300$. Similar results have been achieved in the UK as well. ${ }^{21}$ The input data of the study has been based on the FAIR-HF trial, and the ICER of the FCM treatment compared with placebo has been of $€ 4,414$ per quality-adjusted life-year (QALY). Studies performed in Spain point in the same direction ${ }^{22}$; the cost of 1 QALY has been of $€ 6,123.78$, again, under the NICE threshold. The time horizon in this case has been of 24 weeks. The same time horizon has been used for a Swedish study as well, ${ }^{23}$ based on the FAIR-HF trial. The ICER in case of the Swedish setting has been of $€ 8,194$ per QALY, much below the NICE threshold. The cost-effectiveness of FCM compared to no treatment seems to be converging towards similar values all over Europe; the cost-effectiveness study performed in Greece shows similar results. ${ }^{24}$ The study was based on the FAIR-HF trial for a 24-week time horizon, and the resulting ICER has been of $€ 25,506$ per QALY for administration in a day-case unit and $€ 5,368$ per QALY for administration in the hospital outpatient department. Compared to the European setting, studies performed in South Korea show a much higher ICER. ${ }^{25}$ In case of this study with a time horizon of 24 weeks, based on the FAIR-HF trial, the ICER has been of $\$ 22,192$, but it is still lower than the NICE threshold. Cost-effectiveness studies are a crucial aspect of decision-making, and such analysis could be performed in Romania based on the findings of the present study.

In comparison with the majority of these studies, the present study follows a period of 52 weeks, based on the CONFIRM-HF study.

Iron deficiency is an important comorbidity in CHF, and according to the current guidelines of the European Society of Cardiology, CHF should be routinely screened 
in newly diagnosed patients and properly managed to alleviate symptoms and generate health gain on CHF patients. ${ }^{26}$

\section{LIMITATIONS}

One of the key limitations of the present study is that since in Romania there is no patient registry for CHF, some key parameters of the calculations have been based on the budget impact model developed by Theidel et al., which, in turn, were based on data coming from clinical studies and trials (including the probabilities for the patients to be in a specific NYHA class, death over time, rate of hospitalization due to the worsening $\mathrm{CHF}$, and average length of stay) and may not be in accordance with the real-world treatment patterns or the real-world behavior of the Romanian doctors.

Another limitation of the study is the use of direct reimbursement fees as costs in case of outpatient care, as there is no information regarding the actual costs of this type of care.

\section{CONCLUSIONS}

By treating patients with FCM, the signs and symptoms of CHF can be improved, and the duration and frequency of hospitalizations can be reduced. This added clinical benefit can be achieved at a cost of $€ 37$ per patient for the no-Clawback scenario and a cost reduction of $€ 9$ for the Clawback scenario. Our analysis confirms that the unmet need of CHF patients with ID can be met by the treatment with FCM at a minimal additional cost.

\section{CONFLICT OF INTEREST}

None to be declared.

\section{ACKNOWLEDGEMENT}

Syreon Research Romania gratefully acknowledges the financial support of Vifor Romania.

\section{REFERENCES}

1. Kemp CD, Conte JV. The pathophysiology of heart failure. Cardiovasc Pathol. 2012;21:365-371. doi: 10.1016/j. carpath.2011.11.007.

2. Lloyd-Jones DM, Larson MG, Leip EP, et al. Lifetime Risk for Developing Congestive Heart Failure. Circulation. 2002;106:3068-3072. doi: 10.1161/01. CIR.0000039105.49749.6F.
3. Bredy C, Ministeri M, Kempny A, et al. New York Heart Association (NYHA) classification in adults with congenital heart disease: relation to objective measures of exercise and outcome. Eur Heart J Qual Care Clin Outcomes. 2018;4:51-58. doi: 10.1093/ehjqcco/qcx031.

4. Chioncel O, Tatu-Chitoiu G, Christodorescu R, et al. Characteristics of patients with heart failure from Romania enrolled in - ESC-HF Long-Term (ESC-HF-LT) Registry. Romanian Journal of Cardiology. 2015;25:413-420.

5. Sinescu C, Axente L. Heart failure - concepts and significance. Birth of a prognostic model. J Med Life. 2010;3:421-429.

6. Pop D, Penciu OM, Sitar-Taut AV, Zdrenghea DT. Comparative heart failure profile over a 3-year period in a Romanian general hospital. Clin Interv Aging. 2013;8:999-1005. doi: 10.2147/CIA.S46760.

7. Klip IT, Comin-Colet J, Voors AA, et al. Iron deficiency in chronic heart failure: An international pooled analysis. Am Heart J. 2013;165:575-82.e3. doi: 10.1016/j.ahj.2013.01.017.

8. Cleland JGF, Zhang J, Pellicori P, et al. Prevalence and Outcomes of Anemia and Hematinic Deficiencies in Patients With Chronic Heart Failure. JAMA Cardiol. 2016;1:539-547. doi: 10.1001/jamacardio.2016.1161.

9. Okonko DO, Mandal AKJ, Missouris CG, Poole-Wilson PA. Disordered iron homeostasis in chronic heart failure: prevalence, predictors, and relation to anemia, exercise capacity, and survival. J Am Coll Cardiol. 2011;58:1241-1251. doi: 10.1016/j.jacc.2011.04.040.

10. Jankowska EA, Rozentryt P, Witkowska A, et al. Iron deficiency: an ominous sign in patients with systolic chronic heart failure. Eur Heart J. 2010;31:1872-1880. doi: 10.1093/eurheartj/ehq158.

11. Comín-Colet J, Enjuanes C, González G, et al. Iron deficiency is a key determinant of health-related quality of life in patients with chronic heart failure regardless of anaemia status. Eur J Heart Fail. 2013;15:1164-1172. doi: 10.1093/eurjhf/hft083.

12. Dalal J, Katekhaye V, Jain R. Effect of ferric carboxymaltose on hospitalization and mortality outcomes in chronic heart failure: A meta-analysis. Indian Heart J. 2017;69:736-741. doi: 10.1016/j.ihj.2017.10.009.

13. Anker SD, Comín-Colet J, Filippatos G, et al. Ferric Carboxymaltose in Patients with Heart Failure and Iron Deficiency. N Engl J Med. 2009;361:2436-2448. doi: 10.1056/ NEJMoa0908355.

14. Ponikowski P, van Veldhuisen DJ, Comín-Colet J, et al. Beneficial effects of long-term intravenous iron therapy with ferric carboxymaltose in patients with symptomatic heart failure and iron deficiency. Eur Heart J. 2015;36:657-668. doi: 10.1093/eurheartj/ehu385.

15. Hotărârea de Guvern nr. Nr. 140/2018 din 21 martie 2018 publicată în Monitorul Oficial al României Partea I, nr. 270 din 27 martie 2018. Available at: http://www.casan.ro/casalba/ media/postFiles/HG\%20140-CONTRACT\%20CADRU\%20 2018-2019.pdf

16. Ordinul ministrului sănătății și al președintelui Casei Naționale de Asigurări de Sănătate nr. 397/836/2018 privind aprobarea Normelor metodologice de aplicare în anul 2018 a Hotărârii Guvernului nr. 140/2018 pentru aprobarea pachetelor de servicii și a Contractului-cadru care reglementează condițiile acordării asistenței medicale, a medicamentelor și a dispozitivelor medicale în cadrul sistemului de asigurări sociale de sănătate pentru anii 2018-2019. Available at: 
http://www.cnas.ro/casgorj/media/postFiles/Ordin\%20397836_2018\%20(actualizat\%20cu\%20Ordin\%20MS-CNAS\%20 910-1161_2018).pdf

17. Theidel $\mathrm{U}$, Väätäinen S, Martikainen J, Soini E, Hardt T, Doehner W. Budget impact of intravenous iron therapy with ferric carboxymaltose in patients with chronic heart failure and iron deficiency in Germany. ESC heart failure. 2017;4:274281. doi: 10.1002/ehf2.12179.

18. Bourguignon S, Faller M, Champs F-O, et al. Budget impact of intravenous ferric carboxymaltose in patients with chronic heart failure and iron deficiency in France. ESC Heart Fail. 2019;6:559-569. doi: 10.1002/ehf2.12432.

19. Ressl S, Walter E, Bauer M. Budget-Impact-Analysis of Iron Treatment Using Intravenous Ferric Carboxymaltose In Patients With Chronic Heart Failure And Iron Deficiency In Austria. Value Health. 2015;18:A384. doi: 10.1016/j. jval.2015.09.831.

20. Walter E, Bauer M, Ressl S. Cost-Effectiveness Of Ferric Carboxymaltose In Patients With Iron Deficiency And Chronic Heart Failure In Austria. Value Health. 2015;18:A392. doi: 10.1016/j.jval.2015.09.876.

21. Gutzwiller FS, Schwenkglenks M, Blank PR, et al. Health economic assessment of ferric carboxymaltose in patients with iron deficiency and chronic heart failure based on the FAIR-HF trial: an analysis for the UK. Eur J Heart Fail. 2012;14:782-790. doi: 10.1093/eurjhf/hfso83.
22. Comín-Colet J, Rubio-Rodríguez D, Rubio-Terrés C, et al. A Cost-effectiveness Analysis of Ferric Carboxymaltose in Patients With Iron Deficiency and Chronic Heart Failure in Spain. Rev Esp Cardiol (Engl Ed). 2015;68:846-851. doi: 10.1016/j.rec.2014.10.010.

23. Hofmarcher T, Borg S. Cost-effectiveness analysis of ferric carboxymaltose in iron-deficient patients with chronic heart failure in Sweden. J Med Econ. 2015;18:492-501. doi: 10.3111/13696998.2015.1029491.

24. Mylonas C, Kourlaba G, Berberian K, Maniadakis N. Economic Evaluation Of Ferric Carboxymaltose In Patients With Chronic Heart Failure And Iron Deficiency: An Analysis For Greece Based On Fair-Hf Trial. Value Health. 2014;17:A486. doi: 10.1016/j.jval.2014.08.1424.

25. Lim EA, Sohn HS, Lee H, Choi SE. Cost-utility of ferric carboxymaltose (Ferinject ${ }^{\circledR}$ ) for iron-deficiency anemia patients with chronic heart failure in South Korea. Cost effectiveness and resource allocation: C/E. 2014;12:19. doi: 10.1186/1478-7547-12-19.

26. Ponikowski P, Voors AA, Anker SD, et al. 2016 ESC Guidelines for the diagnosis and treatment of acute and chronic heart failure: The Task Force for the diagnosis and treatment of acute and chronic heart failure of the European Society of Cardiology (ESC)Developed with the special contribution of the Heart Failure Association (HFA) of the ESC. Eur Heart J. 2016;37:2129-2200. doi: 10.1002/ejhf.592. 